\title{
Influence of discrete fibre reinforcement on the uniaxial compression response and seismic wave velocity of a cement-stabilised sandy-clay
}

\author{
Nuno Cristelo ${ }^{a,}{ }^{*}$, Vítor M.C.F. Cunha ${ }^{b}$, Mónica Dias ${ }^{c}$, António Topa Gomes ${ }^{c}$, \\ Tiago Miranda ${ }^{\mathrm{b}}$, Nuno Araújo ${ }^{\mathrm{b}}$ \\ ${ }^{a}$ C-MADE, School of Science and Technology, University of Trás-os-Montes e Alto, Douro 5000-801, Vila Real, Portugal \\ ${ }^{\mathrm{b}}$ ISISE, Department of Civil Engineering, University of Minho, Campus de Azurém, 4800-058 Guimarães, Portugal

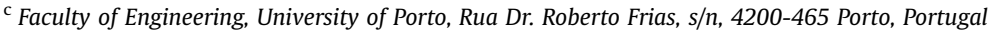

\section{A R T I C L E I N F O}

\section{Article history:}

Received 26 July 2014

Received in revised form

1 November 2014

Accepted 18 November 2014

Available online 3 December 2014

\section{Keywords:}

Geosynthetics

Soil improvement

Fibre reinforcement

Ultrasound testing

Uniaxial compression strength

\begin{abstract}
A B S T R A C T
A sandy clay from the northeast region of Portugal has been reinforced with polypropylene fibres and cement, and seismic wave velocity measurements and uniaxial compression strength tests were performed. Results showed that the fibre induce variations on the wave's velocity that cannot be related to real changes in the material stiffness. Therefore, care should be used when using this technique in fibre reinforced soils. The addition of fibres resulted in an increase of compression strength of the mixtures, for every cement content. Regarding the stiffness, the fibres proved to be increasingly effective with an increase in cementation, especially at the early stages of the stress-strain curve, when the secant deformability modulus increases with fibre content. However, no influence of the discrete reinforcement was detected on the peak and post-peak stages of the loading process. Fibre length showed also to be influential on strength and stiffness.
\end{abstract}

๑) 2014 Elsevier Ltd. All rights reserved.

\section{Introduction}

Short and randomly distributed fibres are often used to reinforce brittle materials, due to their decisive contribution to the delay of crack initiation and, especially, crack propagation. The appearance of fibre reinforced concrete dates back to the early sixties (ACI 544, 2002), and nowadays is widely used on full load bearing structural applications of laminar structures, e.g. tunnels, bridges and industrial slabs on-grade. Moreover, the use of fibres in cementicious materials is not restricted to structural applications, since they are also frequently used in coating mortars of façades to prevent cracking due to shrinkage and thermal loads. The use of fibres in brittle materials is relatively old when compared to the advent of fibre reinforced concrete and, even more so, of fibre reinforced soil, since this solution was popular in ancient civilizations, which used either straw or bamboo fibres to reinforce lime and soil mortars.

Several types of fibres are used in the construction industry to reinforce cement based materials, e.g. steel, polypropylene, glass and carbon fibres (ACI 544, 2002). Nonetheless they are not

\footnotetext{
* Corresponding author. Tel.: +351259350388; fax: +351 259350356 .

E-mail address: ncristel@utad.pt (N. Cristelo).
}

constrained to inorganic materials. Within a sustainability perspective, the use of natural fibres in the reinforcement of cementicious materials is gathering some expression. Examples of the aforementioned are the research studies regarding the use of recycled micro-cellulose fibres (Mohamed et al., 2010), as well as other plant fibres, such as eucalyptus pulp, coir or eucalyptus (Savastano et al., 1999), sisal (Silva et al., 2010), kenaf (i.e. hibiscus cannabinus) (Elsaid et al., 2011), cotton (Pinto et al., 2013), or even other unforeseeable materials, such as human hair (Jain and Kothari, 2012).

More recently, an increasing interest in the use of discrete fibres in soil reinforcement has been reported, partially driven by the successful results achieved with concrete, but also as a result of its wide dissemination throughout the construction industry. In the past few decades, several studies have been conducted to assess the structural benefits of reinforcing soils with randomly distributed discrete fibres. Uniaxial and triaxial compression and direct shear behaviour have been thoroughly analysed (Al-Refeai, 1991; Chauhan et al., 2008; Consoli et al., 2010, 1999, 1998; Diambra et al., 2010; Fatahi et al., 2012; Hamidi and Hooresfand, 2013; Lovisa et al., 2010; Michalowski and Čermák, 2003; Miller and Rifai, 2004; Ranjan et al., 1996; Tang et al., 2007; Yetimoglu and Salbas, 2003). Polypropylene fibres are predominantly used for 
soil reinforcement, with fibre contents ranging from $0.05 \%$ to $3 \%$. Glass fibres were also used in some earlier studies (Al-Refeai, 1991; Consoli et al., 1999, 1998). However, they were quickly abandoned, probably due to the fact that the glass used in the earlier fibres was not alkali-resistant (AR). Even with AR-glass fibres, which are found to be stable in Portland cement-based matrices, both a strength and ductility reduction was observed when the fibre reinforced composite was exposed to moist environments over long periods (Kopecskó, 2004). Tire fibres have also been studied for soil reinforcement, and Edinçliler and Ayhan (2010) have found a strong correlation between fibre aspect ratio and shear strength in granular soils.

The benefits promoted by the fibres, regarding mechanical properties, are mainly due to the fibres crossing micro/macro cracks. These fibres guarantee a certain level of stress transfer between both faces of the crack, providing a residual strength to the composite, with magnitude depending on a multiplicity of interconnected mechanisms and factors. Within these factors, the fibre (i.e. material, geometry and fibre content), the soil matrix and the fibre/soil interface properties, as well as fibre distribution and orientation, may be highlighted (Banthia and Trottier, 1994; Cunha et al., 2011, 2010; Naaman and Najm, 1991; Tang et al., 2010). In general, the fibre addition to a soil matrix leads to an increase in uniaxial compression strength, in terms of peak and especially in terms of residual strength (post-cracking). When the soil is also stabilised with a cementitious binder, like cement, then the level of improvement is intrinsically connected to both fibre and cement content. Nevertheless, some authors (Hamidi and Hooresfand, 2013; Tang et al., 2007) have observed a reduction of the stiffness of fibre reinforced soils with the inclusion of fibres, which was attributed to the reduction in brittleness.

In the present work, the influence of synthetic discrete fibres $(0.10,0.15$ and $0.25 \%$ by dry weight) and Portland cement $(0,5$ and $10 \%$ by dry weight) on the mechanical properties of clayey soils, was assessed. An extensive experimental campaign was carried out. In a first stage, a thorough characterization of the soil used in this research was performed, including its main geotechnical and microstructural properties, using scanning electron microscope (SEM), X-ray energy dispersive spectrometry (EDS) analysis and Xray diffraction mineralogical identification (XRD). The stress-strain response of the material was then thoroughly assessed using nondestructive ultrasonic pulse tests and uniaxial compression tests. The main motivation for this research was the contribution for a clearer definition of the response of low to highly cemented soils, when reinforced with polypropylene fibres. The choice of the modulus as a primary concern is related to the importance of such parameter in structural design, associated with the difficulties regarding its experimental assessment. It is essential that the complex behaviour of this two-phase material (soil + fibre) is well understood and also that simple experimental techniques are used properly and correctly interpreted.

\section{Methodology}

\subsection{Materials characterisation}

The soil was collected from a location inside the Campus of the University of Trás-os-Montes e Alto Douro (UTAD), in the north of Portugal. Geotechnical characterisation was performed according with BSi 1377-1 (1990), BSi 1377-2 (1990) and BSi 1377-4 (1990) standards. Fig. 1 and Table 1 summarise the obtained results. Based on the properties shown in Table 1, the soil was classified as CL - Sandy Lean Clay, according to ASTM D2487 (2011).

The SEM analyses were performed on a FEI QUANTA - 400 electronic microscope, with a tungsten filament electron source

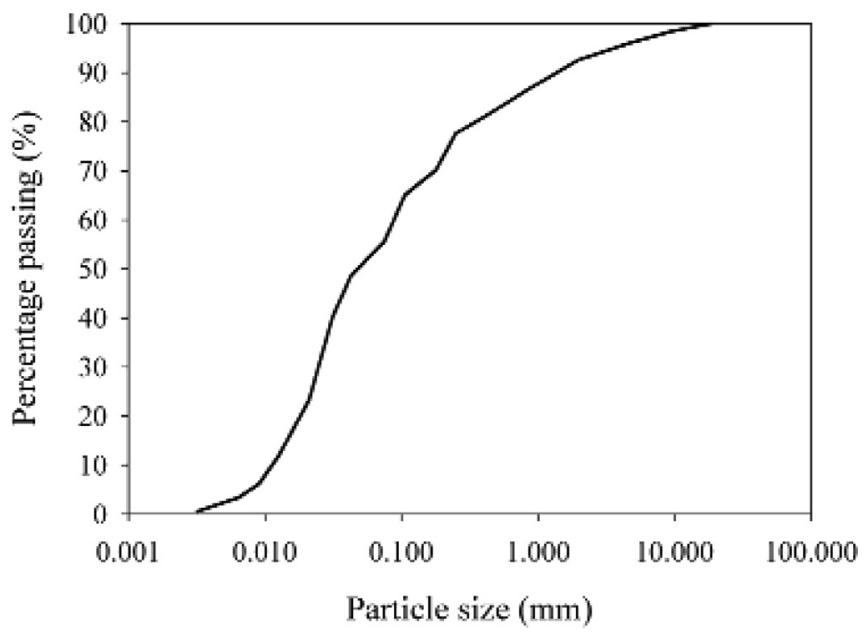

Fig. 1. Grain size distribution of the soil.

and $29.97 \mathrm{kV}$ accelerating voltage, and conducted in low vacuum mode. An X-ray energy dispersive spectrometry (EDS) system from EDAX was used to analyse the chemical composition of the original soil and also of the soil-cement mixture after 28 days curing (Table 2). The EDS results presented correspond to the average values of five different acquisition points, performed over three different specimens. An input count-rate of 300 counts per second was used, with a mean acquisition time of 150 s to accumulate each spectrum. EDS data revealed that almost $80 \%$ of the soil is made of silica and alumina, while the addition of cement contributed, as expected, to a significant increase in the calcium content, relatively to the original soil composition (Fig. 2).

The minerology was examined by a PANalytical X'Pert Pro diffractometer, fitted with an $\mathrm{X}^{\prime}$ Celerator detector. The scans covered the range $7-77^{\circ} 2 \theta$, with a nominal step size of $0.017^{\circ} 2 \theta$ and time of $100 \mathrm{~s}$ per step. CuK $\alpha$ radiation, with a wavelength of $\lambda=1.54180 \AA$, was used. Qualitative phase identification was carried out using High Score Plus software and the International Centre for Diffraction Data Database, Sets 1-49 [ICDD, 1999]. The X-Ray diffraction patterns (Fig. 3) of the soil and the soil-cement mixture showed the presence of quartz, calcite, illite, nacrite and muscovite on the mineralogical composition, which are common for this type of soil.

A Portland cement CEM I-42.5R was used. The fibres were made of polypropylene $\left(\mathrm{C}_{3} \mathrm{H}_{6}\right)$ and specifically cut having in mind their application in concrete and mortar, for enhanced impact on strength and crack resistance. Table 3 presents their main properties, accordingly to the manufacture's specification sheet. Due to the well-known difficulty to achieve proper homogenisation in the soil-fibre mixture (Ibraim et al., 2012), a preliminary separation of the fibres, prior to the mixing process, assumes a key role. Therefore, compressed air was injected in a chamber containing the

Table 1

Main geotechnical properties of the soil.

\begin{tabular}{lcl}
\hline Plastic limit & 14.59 & $\%$ \\
Liquid limit & 23.46 & $\%$ \\
Organic matter content & 2.64 & $\%$ \\
Specific gravity & 26.83 & $\mathrm{kN} / \mathrm{m}^{3}$ \\
$D_{50}$ & 0.045 & $\mathrm{~mm}$ \\
Fines fraction (sieve $\mathrm{N}^{\circ}$ 200) & 55.6 & $\%$ \\
Uniformity coefficient & 6.92 & \\
Curvature coefficient & 0.53 & \\
Optimum water content (Standard Proctor Test) & 13.5 & $\%$ \\
Maximum dry unit weight (Standard Proctor Test) & 18.9 & $\mathrm{kN} / \mathrm{m}^{3}$ \\
\hline
\end{tabular}


Table 2

Chemical composition of the soil and the soil-cement mixture at 28 days curing (\% wt).

\begin{tabular}{llllllllll}
\hline Element & $\mathrm{SiO}_{2}$ & $\mathrm{Al}_{2} \mathrm{O}_{3}$ & $\mathrm{Fe}_{2} \mathrm{O}_{3}$ & $\mathrm{CaO}$ & $\mathrm{K}_{2} \mathrm{O}$ & $\mathrm{TiO}_{2}$ & $\mathrm{MgO}$ & $\mathrm{Na}_{2} \mathrm{O}$ & $\mathrm{SO}_{3}$ \\
\hline Original soil & 61.30 & 16.60 & 11.14 & - & 6.78 & 1.59 & 1.83 & 0.76 & - \\
Soil-cement & 45.84 & 19.10 & 10.83 & 13.46 & 6.78 & 1.56 & 1.26 & - & 1.16 \\
\hline
\end{tabular}
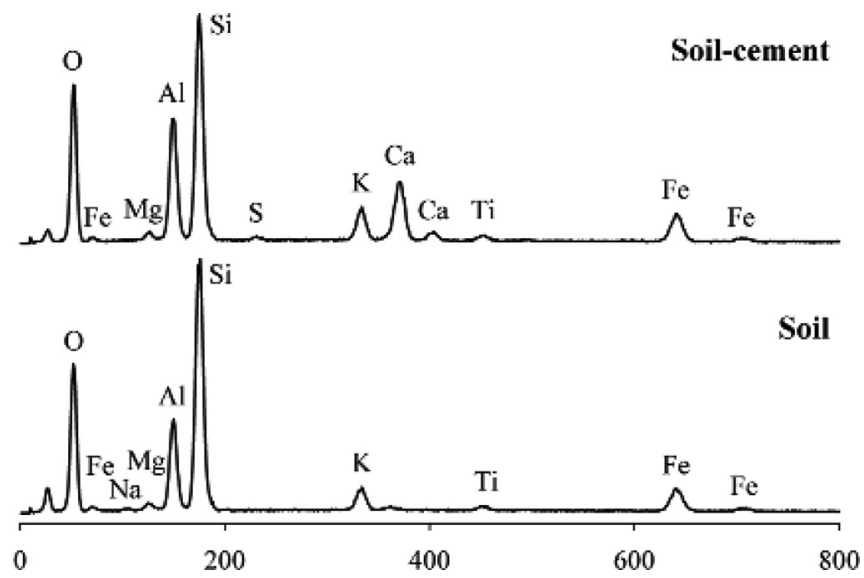

Fig. 2. EDS analysis of the original soil and the soil-cement (10\%) mixture after 28 days curing.

original fibres for $5 \mathrm{~min}$. The fibres before and after the separation procedure are shown in Fig. 4.

\subsection{Specimen characterisation, preparation and testing}

The preparation of the soil started with air-drying for at least $48 \mathrm{~h}$, after which de-flocculation of the particles was carried out by hand, before a further $24 \mathrm{~h}$ drying period, although this time it happened in the oven, at $100{ }^{\circ} \mathrm{C} \pm 5{ }^{\circ} \mathrm{C}$. When preparing the soil-cement specimens, the solids (soil + cement) were mixed together for $10 \mathrm{~min}$ in a Hobart counter mixer. Two different cement/soil/weight ratios of $5 \%$ and $10 \%$ were prepared. The fibres were carefully added, by hand, to the soil or soil-cement mixture, in fibres/solids weight ratios of $0.10 \%, 0.15 \%$ and $0.25 \%$. A period of 10 min of mechanical mixing followed. Deionised water was the last component to be added, thus requiring an additional mixing period of $10 \mathrm{~min}$.

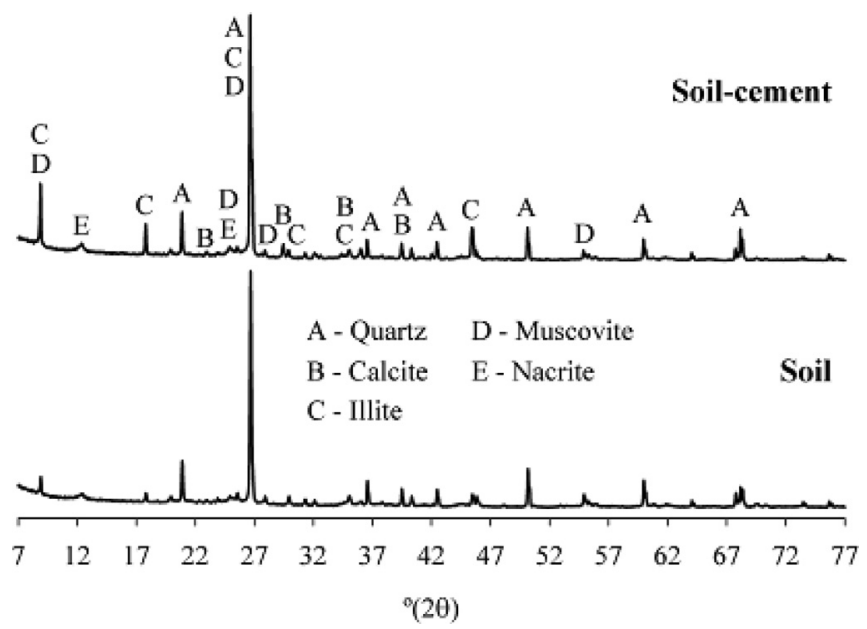

Fig. 3. $\mathrm{Cu} \mathrm{K} \alpha$ diffractogram of the original soil and the soil-cement (10\%) mixture after 28 days curing.
Table 3

Properties of the fibres used, according to factory specifications.

\begin{tabular}{lll}
\hline Average diameter & 31 & $\mu \mathrm{m}$ \\
Length & $12 / 49$ & $\mathrm{~mm}$ \\
Shape & Curly & \\
Density & 910 & $\mathrm{~kg} / \mathrm{m}^{3}$ \\
Moist absorption & Null & \\
Colour & White & \\
Maximum service temperature & 145 & ${ }^{\circ} \mathrm{C}$ \\
Characteristic tensile strength & 0.166 & $\mathrm{~N}$ \\
Characteristic tensile strain & 111.1 & $\%$ \\
\hline
\end{tabular}

Fig. 5 shows microscopically enhanced images of the original soil and the respective mixtures with cement, fibres and cement + fibres. According to Ibraim et al. (2012), the void ratio of the compacted specimen can be measured by considering the fibres as part of the voids or part of the solids, resulting in a difference not higher than $5 \%$. In the present work, and for quantification purposes, the fibres were considered as part of the solids content.

After the mixing procedure was completed, the resulting homogenised material was immediately used to fabricate the necessary specimens. Every specimen was moulded with a water content of $16.0 \%$, a dry unit weight of $18.0 \mathrm{kN} / \mathrm{m}^{3}$ and a void ratio of 0.4906 (considering the fibres' mass as part of the solids content). The water content and dry unit weight values were above and below the optimum determined through the Proctor test, respectively. The reason for this was the need for an additional liquid phase for homogenisation purposes, and this increase in the water content resulted also in a decrease in the dry unit weight, in order to keep the moulding point on the Proctor curve. Although the mixtures without fibres did not require such increase in water content, it was decided, for comparison purposes, to maintain the moulding values for all the mixtures prepared, i.e. with or without fibres. Previous research (Nataraj and McManis, 1997) was able to conclude that no significant modifications in the unit density should be expected by the addition of fibres. The composition of all the mixtures is summarised in Table 4.

To fabricate the uniaxial cylindrical test specimens $(70 \mathrm{~mm}$ diameter $\times 140 \mathrm{~mm}$ height), the mixture was compacted in three layers by moist tamping, with the corresponding predetermined dry unit weight. The general result, regarding the distribution of fibres in the soil-cement matrix, is presented in Fig. 6, showing a D.1.1 specimen. From the image presented it appears that the fibres

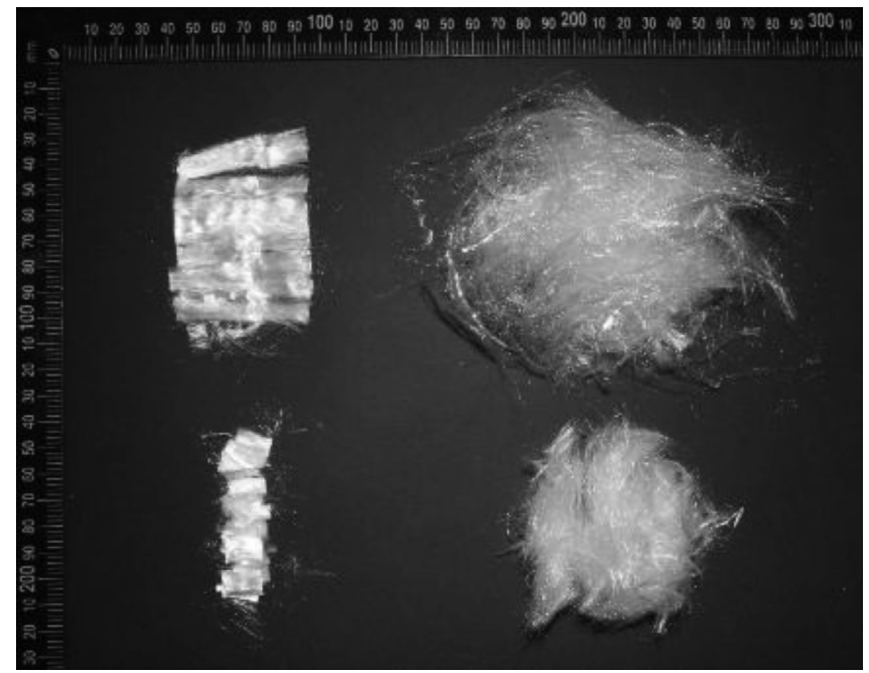

Fig. 4. Both types of fibres before and after separation inside a compressed air chamber. 
have a preferred horizontal orientation, which is not surprising considering the process of fabrication of the specimens - moist tamping - during which a static stress is applied along the longitudinal axis of the cylindrical specimen. Ibraim et al. (2012) and Muir Wood et al. (2007) concluded that such procedure produces a preferred near-horizontal orientation of the fibres.

After compaction, the top and bottom of the moulds were covered with cling film, to minimise moisture loss and to assist with the cement hydration process, and were then stored in a humid chamber at $20^{\circ} \mathrm{C} \pm 1{ }^{\circ}$ and $90 \% \mathrm{RH} \pm 3 \%$. After $48 \mathrm{~h}$ the specimens were demoulded and again wrapped in cling film and stored back in the humid chamber for the remaining of the curing period. A single curing period of 28 days was considered.

After unwrapped, and before tested, the specimen's weight and dimensions were carefully measured. An Instron $^{\circledR}$ electromechanical testing rig, fitted with a $100 \mathrm{kN}$ load cell, was used for the compression tests. These tests were carried out under monotonic displacement control at a rate of $0.2 \mathrm{~mm} / \mathrm{min}$, and the entire stress-strain curve was obtained from each test. The specimen's deformation was obtained by averaging the readouts of two Linear Variable Differential Transformers (LVDT). Three specimens per mixture were prepared and tested.

Ultrasonic pulse velocity (P-wave) non-destructive measurements were taken on the same specimens used in the uniaxial compression tests, throughout their respective curing period (Fig. 7a). A commercially available equipment was used, consisting of:

- A pair of axially aligned piezoelectric broadband transducers, for measuring P-wave velocities, with a nominal frequency of $54 \mathrm{kHz}$ and $30 \mathrm{~mm}$ in diameter (Fig. 7b).

- A waveform generator; an amplifier and an interval timer with a direct reading digital display, which showed the P-wave velocity
Table 4

Identification and characterisation of all the mixtures fabricated.

\begin{tabular}{llcll}
\hline Label & $\begin{array}{l}\text { Fibre }^{\mathrm{a}, \mathrm{b}} \\
\text { content (\%) }\end{array}$ & $\begin{array}{l}\text { Cement } \\
\text { content }(\%)\end{array}$ & $\begin{array}{l}\text { Fibre } \\
\text { length }(\mathrm{mm})\end{array}$ & $\mathrm{W} / \mathrm{c}$ \\
\hline A.0 & 0.0 & 0.0 & - & 0.000 \\
A.1 & 0.0 & 5.0 & - & 3.200 \\
A.2 & 0.0 & 10.0 & - & 1.600 \\
B.0.1 & 0.10 & 0.0 & 12.9 & 0.000 \\
B.1.1 & 0.10 & 5.0 & 12.9 & 3.197 \\
B.2.1 & 0.10 & 10.0 & 12.9 & 1.598 \\
B.0.2 & 0.10 & 0.0 & 49.54 & 0.000 \\
B.1.2 & 0.10 & 5.0 & 49.54 & 3.197 \\
B.2.2 & 0.10 & 10.0 & 49.54 & 1.598 \\
C.0.1 & 0.15 & 0.0 & 12.9 & 0.000 \\
C.1.1 & 0.15 & 5.0 & 12.9 & 3.195 \\
C.2.1 & 0.15 & 10.0 & 12.9 & 1.598 \\
C.0.2 & 0.15 & 0.0 & 49.54 & 0.000 \\
C.1.2 & 0.15 & 5.0 & 49.54 & 3.195 \\
C.2.2 & 0.15 & 10.0 & 49.54 & 1.598 \\
D.0.1 & 0.25 & & 12.9 & 0.000 \\
D.1.1 & 0.25 & 0.0 & 12.9 & 3.192 \\
D.2.1 & 0.25 & 5.0 & 12.9 & 1.596 \\
D.0.2 & 0.25 & 10.0 & 49.54 & 0.000 \\
D.1.2 & 0.25 & 0.0 & 49.54 & 3.192 \\
D.2.2 & 0.25 & 5.0 & 49.54 & 1.596 \\
\hline a. & 10.0 & &
\end{tabular}

a Relatively to the soil + cement weight.

b Considering the fibres as part of the solids content.

$\left(v_{\mathrm{p}}\right)$ in real time. An oscilloscope would have been preferable, due to the lower definition of the pulse wave when travelling through heterogeneous materials, like soil. However, such equipment was not available.

The equipment has an excitation voltage of $1000 \mathrm{~V}$ and a resolution of $0.1 \mu \mathrm{s}$. Although it was initially developed for concrete
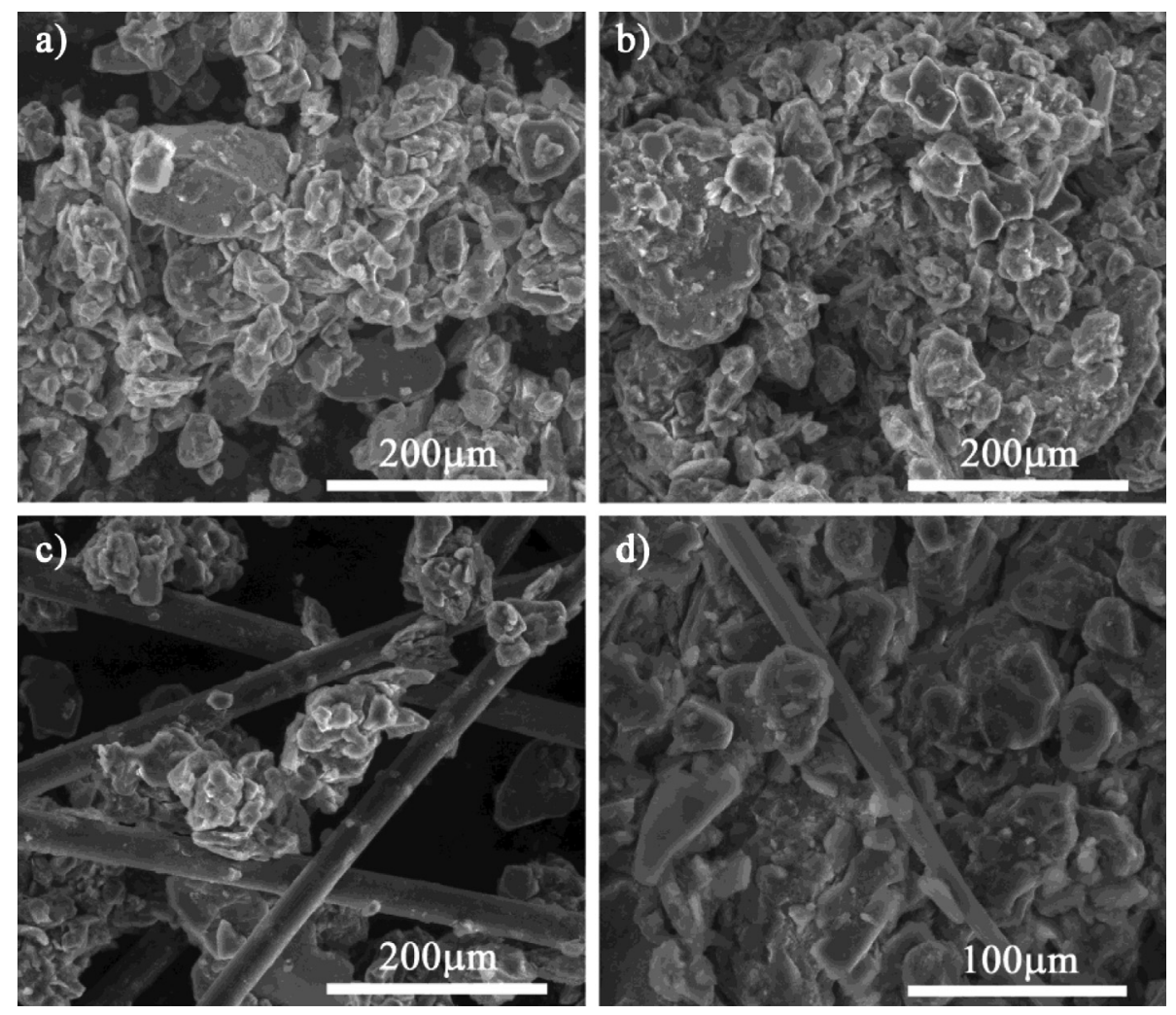

Fig. 5. SEM micrographs of the (a) original soil; (b) soil and $10 \%$ cement; (c) soil and $0.25 \%$ fibres; (d) soil, $10 \%$ cement and $0.25 \%$ fibres. 


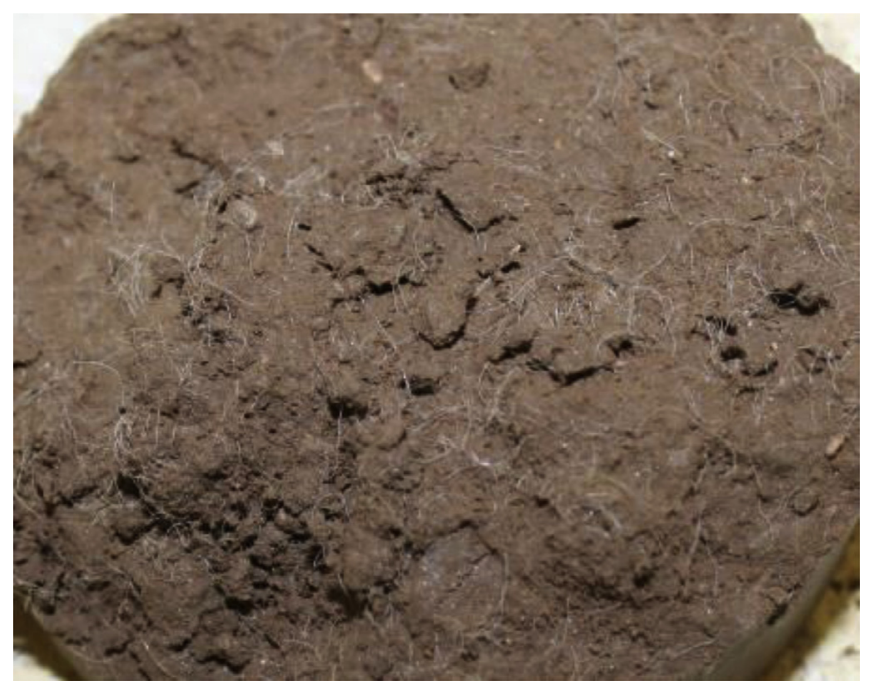

Fig. 6. General view of the fibres' distribution after moulding one of the D.1.1 specimens.

analysis, the equipment performed in a very consistent and trustworthy manner with the specimens considered in the present study. Standard EN 12504-4 (2003) was used as general reference. Calibration of the transducers was automatically performed by the equipment, using a metallic specimen with a known P-wave travelling time of $20.9 \mu \mathrm{s}$ (Fig. 7b). The measurements were taken along the longitudinal axis of the specimens, with the specimen vertically aligned and the transducers installed on opposite faces, therefore with a path length of approximately $140 \mathrm{~mm}$. The exact travelling length (specimen's height) and the specimen's weight were measured before each reading, with a precision of $\pm 1 \%$. Transmission and receiving transducers were always located on the bottom and top ends of the specimen, respectively. The acoustic coupling between the transducers and the specimen was obtained using ultrasound gel, while firmly pressing the transducers against the top surfaces of the specimen. The readings were taken at curing periods of $4 \mathrm{~h}, 8 \mathrm{~h}, 12 \mathrm{~h}$ and $24 \mathrm{~h}$, and then once a day during the next 27 days, and each result presented is the average of ten consecutive readings.

\section{Experimental results}

\subsection{Non-destructive ultrasonic tests}

Fig. 8 shows the P-wave velocity evolution of the soil-cementfibre specimens with curing time. The evolution of the $5 \%$ and $10 \%$ cement specimens, without fibre reinforcement, is also presented. The results are normalised by the specimen respective dry unit weight, since it is known that the density has some influence on the wave velocity (Fatahi et al., 2013). Absolute velocity values at 28 days curing are also presented in Table 5. It is possible to observe that the addition of $0.10 \%$ fibres ("B" specimens) clearly and consistently increased the P-wave velocity on all the specimens tested. However, the further addition of fibres, beyond $0.10 \%$, resulted in a decrease of $\mathrm{P}$-wave velocity, with the 0.25 percentage (" $\mathrm{D}$ " specimens) assuming, in general, the lower velocity values. The fact that the results obtained with percentages above $0.10 \%$ are somehow more difficult to sort, might be related to the difficulty in obtaining good homogenisation and, particularly, with the corresponding difficulty in controlling the fibres' orientation. For instance, Fatahi et al. (2013) obtained far more visually clear results when measuring shear wave velocity on soil-cement reinforced with carpet fibre, using $0.5 \%, 0.75 \%$ and $1.00 \%$ fibres. These values represent wider gaps between fibre content, which probably helped to produce non-overlapping curves.

It is well known that the propagation speed of the wave through the material is related to the dynamic modulus, either the deformability modulus $\mathrm{E}$ (P-waves), or the rigidity or shear modulus G (S-waves). However, such relation between wave velocity and stiffness of the material is only valid in continuous media, and the fibres only contribute to increase the heterogeneity, in terms of mass density, of the original soil-cement mixtures.
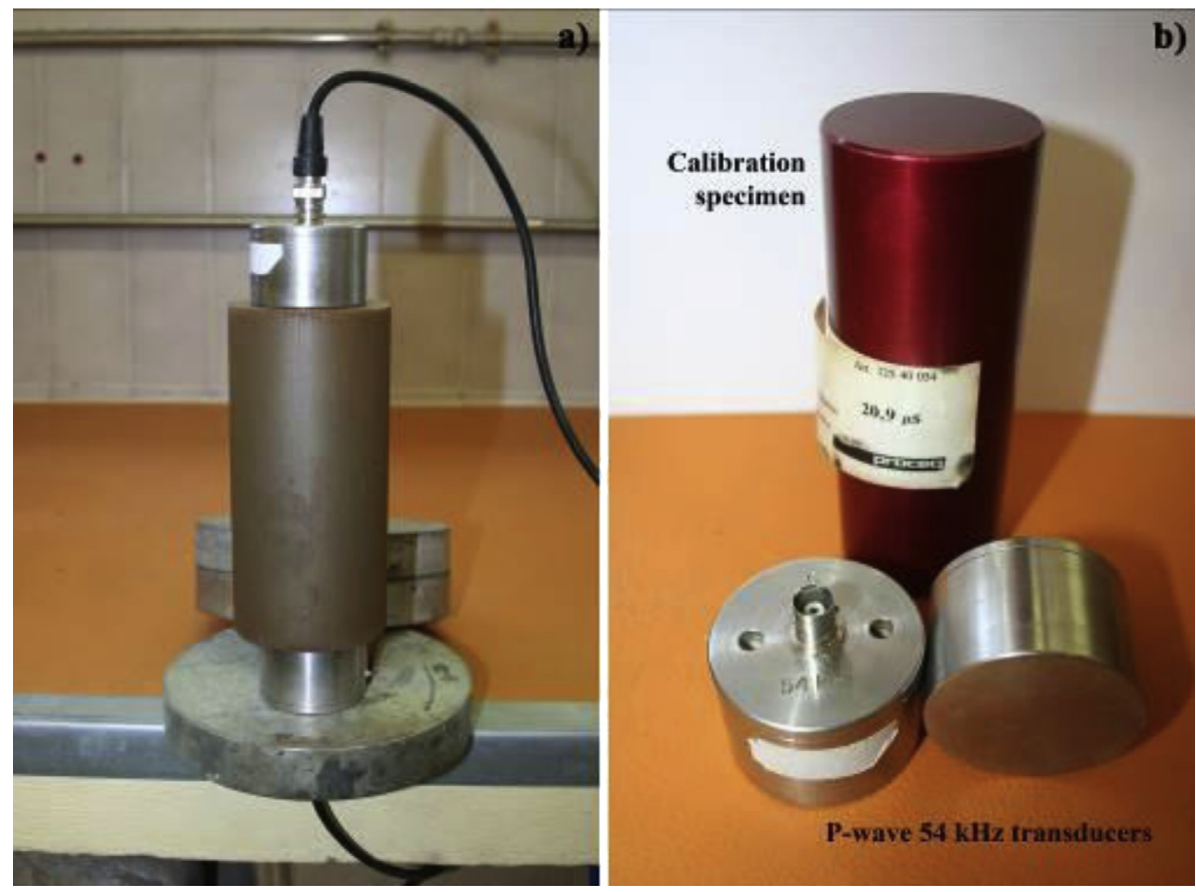

Fig. 7. Setup for the wave velocity measurement (a) and detail of the transducers and calibration specimen (b). 

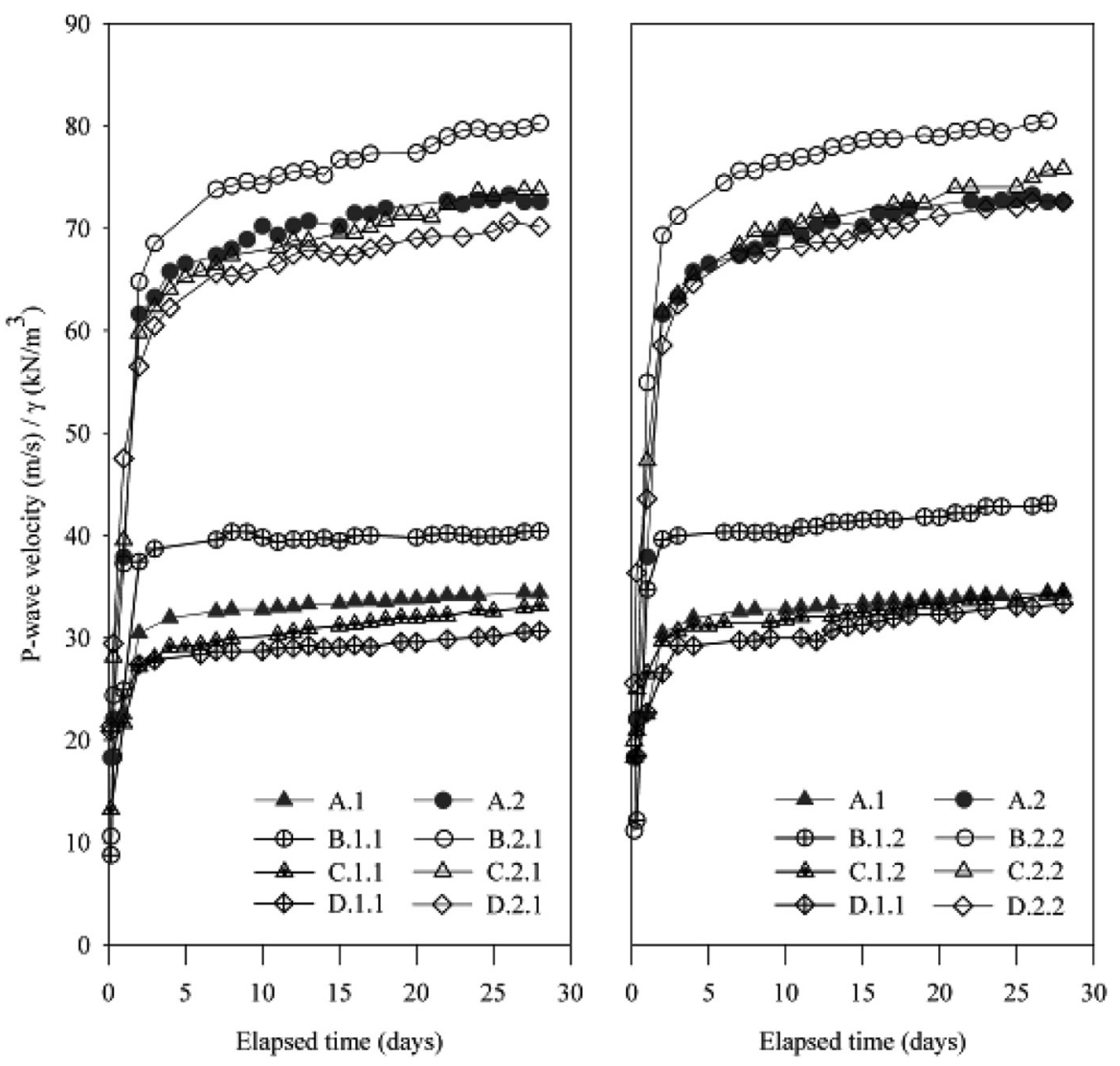

Fig. 8. Evolution of P-wave velocity, normalised by the unit weight, throughout the 28 days curing period.

Although there is no such thing as a truly continuous media in materials science, due to the existence of micro porosity, these flaws in the microstructure homogeneity are enhanced by the addition of the fibres, due not only to the introduction of a different density material, but also to the creation of additional interfaces. Some reasons might explain this fibre influence on the material strength, either separately or in combination:

- The introduction of a more ductile material than the soil-cement matrix creates softer areas along the wave travelling path, continuingly decreasing its energy. Such possibility was advanced by Fatahi et al. (2013), when analysing the decrease of shear wave velocity in soil-cement specimens with increasing carpet fibre content. Contrary to what was seen during the present study, this author obtained a consistent decrease in velocity values for increasing fibre content, which is probably explained by the fact that the lower fibre content considered was $0.50 \%$, well above the $0.10 \%$ that produced an increase in velocity during the present study. This possibility is strengthened by the already mentioned work of Ibraim et al. (2012) and

Table 5

Wave velocities $(\mathrm{m} / \mathrm{s})$ at 28 days curing.

\begin{tabular}{llllll}
\hline \multirow{2}{*}{$\begin{array}{l}\text { Cement } \\
\text { content (wt \%) }\end{array}$} & $\begin{array}{l}\text { Fibre } \\
\text { length (mm) }\end{array}$ & \multicolumn{5}{l}{ Fibre content (wt \%) } \\
\cline { 3 - 6 } & $0.00(\mathrm{~A})$ & $0.10(\mathrm{~B})$ & $0.15(\mathrm{C})$ & $0.25(\mathrm{D})$ \\
\hline 5 & 0 & 644.56 & - & - & - \\
& 12.90 & - & 787.65 & 649.55 & 602.43 \\
& 49.54 & - & 850.68 & 676.90 & 661.01 \\
10 & 0 & 1284.59 & - & - & - \\
& 12.90 & - & 1435.88 & 1450.27 & 1396.99 \\
& 49.54 & - & 1517.49 & 1342.65 & 1432.19 \\
\hline
\end{tabular}

Muir Wood et al. (2007) regarding the orientation of randomly distributed fibres in a soil matrix, whom have concluded that the moist tamping, which was the method applied in the present study, produces a preferred near-horizontal orientation of the fibres, i.e. perpendicular to the wave's path.

- The addition of fibres helps filling some of the voids in the mixture created by the soil particles, thus creating alternative travelling paths; or partially substitutes the higher density soil particles by the lower density fibre particles, therefore decreasing the overall density of the soil-cement matrix (no significant variations of the overall density should be expected, since a certain weight of soil is substituted by the exact weight of fibres). In fact, it is possible that the former explains the increase

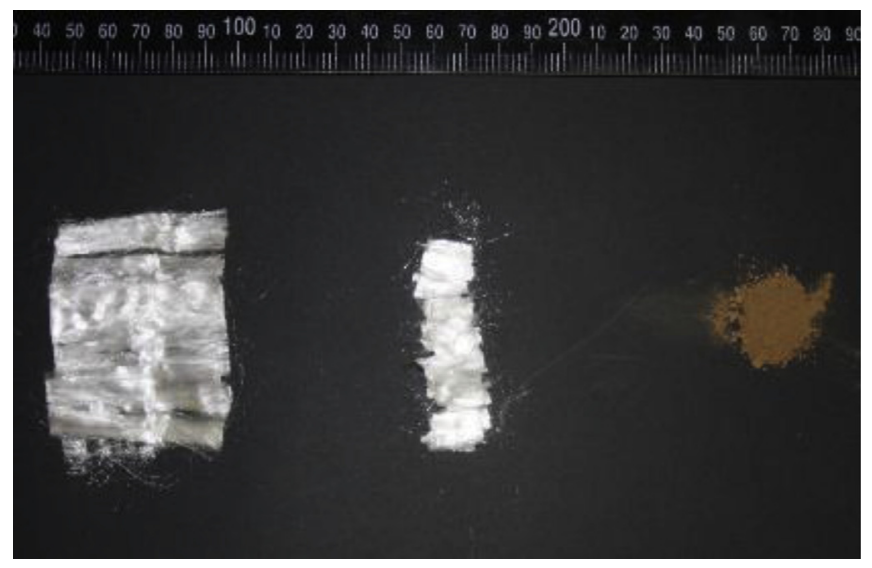

Fig. 9. Visual comparison between the same weight of both types of fibres and soil. 


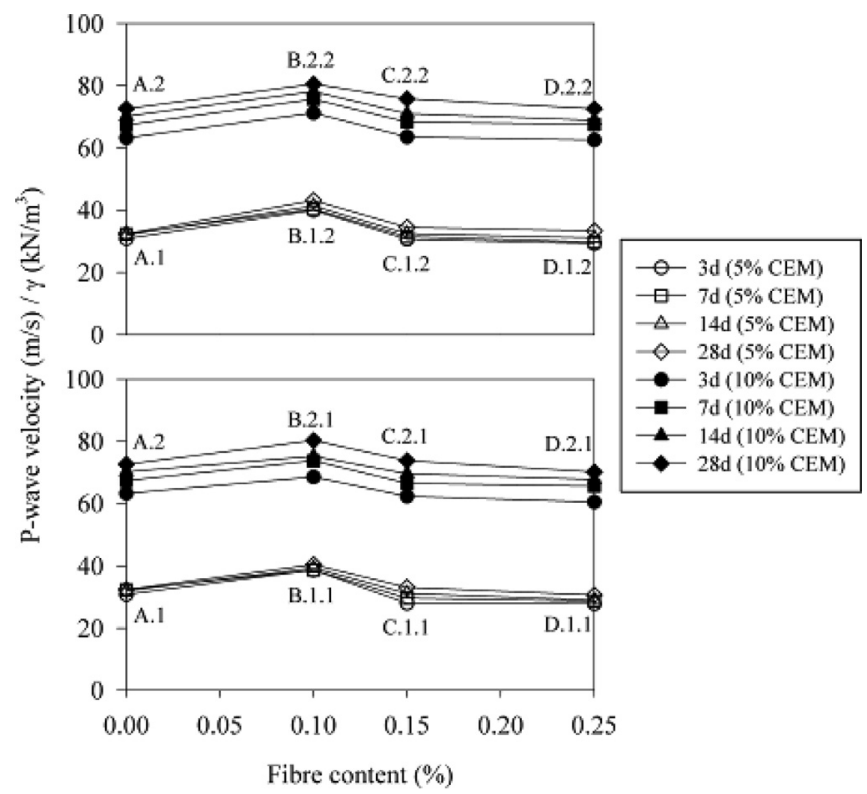

Fig. 10. Evolution of P-wave velocity, normalised by the unit weight, as a function of fibre content.

in velocity with the $0.10 \%$ fibre content, while the latter explains the relative decrease in velocity for the remaining fibre contents. The lower density of the particle fibres, compared with the soil, results in an apparent increase in specific volume. Such relation can be observed in Fig. 9, where the apparent volume of the same weight of soil and particles (before and after separation) is compared. Such increase in the volume occupied by the added

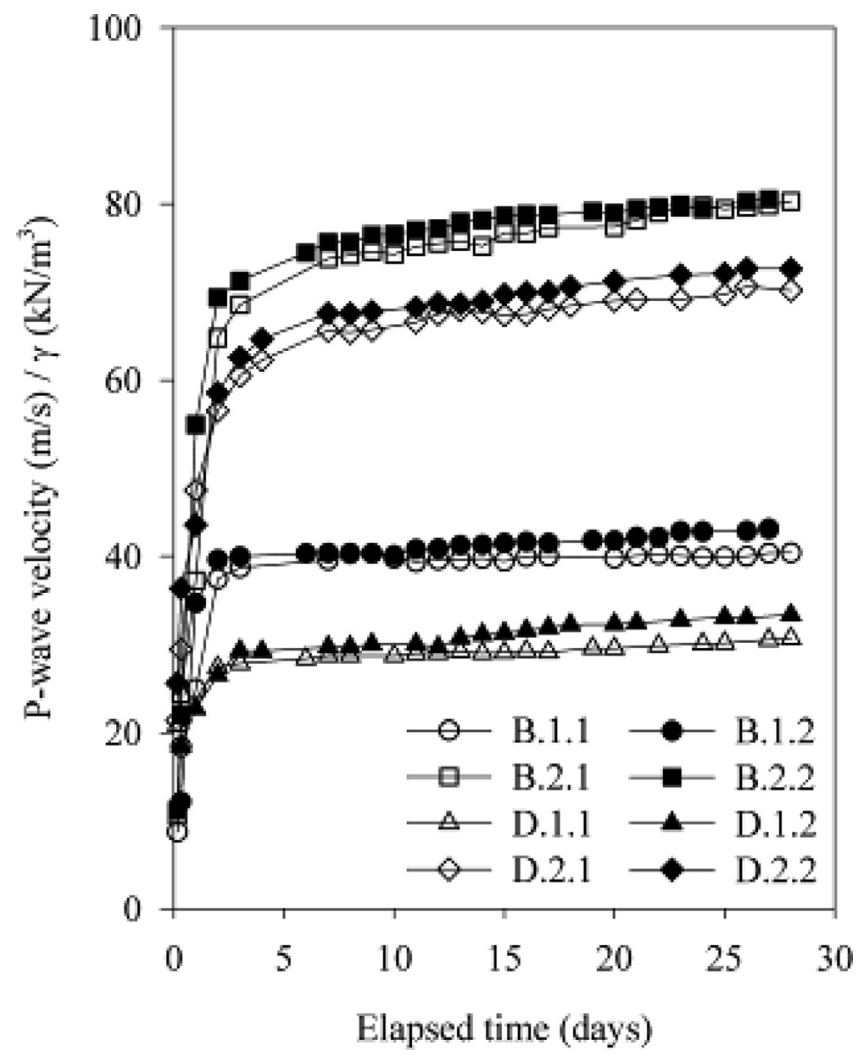

Fig. 11. Influence of fibre length on wave velocity throughout the 28 days curing period. material (fibres) represents a decrease in the number of cemented contact points between particles, which are substituted by contacts between the particles and the fibres, more prone to reduce the wave velocity due to the increase of the interfaces along the wave path.

Therefore, in this case the registered changes in wave velocity are probably not related to changes in the cementitious matrix evolving the fibres, and do not represent a variation of the soil's stiffness, but are instead related to the increased number of "obstacles" in the wave's path. As it is almost impossible to make perfectly homogeneous specimens, the presence of the fibres promote small variations of void ratio and structure which can't be fully controlled. This process produces minor changes in the stiffness at very low strains which are more or less detected by the wave's velocity, depending on the quasi-random distribution of the fibres inside the soil matrix. At larger strains, the tensile stiffness of the fibres has a more influential role on global stiffness, i.e. increasing it. Although this behaviour is important for design purposes, it is not detectable through the measurement of the wave's velocity. Hence, some care should be used when extrapolating any conclusions based on ultrasound results, regarding the mechanical properties of fibre-added materials, since fibre inclusion can affect both the stress-strain response and the wave velocity in different ways. P-wave velocity evolution will be further analysed, in light of the compression strength results.

Fig. 10 shows that the cement hydration reactions, up until the maximum curing period considered of 28 days, did produce a consistent increase in P-wave velocity of each mixture considered. This figure is useful to better visualise the fact that, in general, the increase in fibre content, beyond the $0.10 \%$ value, produced an overall decrease in the velocity values.

Regarding the influence of the fibre length it is possible to conclude, based on Table 5 and Fig. 11, that the higher length fibres $(49.54 \mathrm{~mm})$ consistently produced slightly higher P-wave velocities than those obtained with the lower length fibres $(12.90 \mathrm{~mm})$. Since the fibres have different lengths but equal diameters, a possible explanation for such behaviour is that a higher fibre length means that fewer fibres are introduced in the mixture. This happens because the weight, and not the number of fibres, is used to define the mixture's composition. Therefore, and assuming that a preferential horizontal orientation of the fibres was established as a consequence of the compaction procedure, there are fewer interfaces that the wave needs to cross.

\subsection{Uniaxial compression tests}

Fig. 12 represents all the curves obtained from the UCS tests. In general, these curves highlight the apparent relatively higher influence of the cement content over the fibre content, in terms of stiffness and peak stress. The fact that, for the same stiffness (i.e. cement content), the initial segment of the stress-strain curves is very similar, and therefore independent of the fibre content, was previously observed by Li and Zornberg (2013). These authors sustained that such similar response, at smaller strain levels, is due to the fact that the soil matrix constitutes the major load support, while the fibre's contribution becomes more relevant only at stress levels closer and after peak. In fact, at lower strains the specimen was yet in linear elastic regimen, and therefore the tensile strength of the fibres was not fully mobilised at such early stages. However, a closer look at the evolution of the average deformability secant modulus $\left(E_{50}\right)$, at $50 \%$ of the peak stress (Fig. 13), reveals that the fibre content effect on stiffness appears to increase with the increase in brittleness (which in turn is due to an increase in cement content). The negligible influence of fibre content on the $E_{50}$ 
parameter of the more ductile mixtures ( $0 \%$ cement) was also reported by other authors, through uniaxial or triaxial strength tests, whom concluded that the addition of fibres maintained or reduced the deformability secant modulus (Hamidi and Hooresfand, 2013; Lirer et al., 2011). Such behaviour was attributed to the decrease of the material's brittleness with the progressive increase in fibre content. Another interesting effect of the fibre inclusion was the increase in the post-peak ductility, resulting from the capability of the fibres to absorb the tensile stresses installed in the soil matrix.

One of two factors is usually behind the failure mode of the soil-fibre material: pullout or rupture of the fibres. In this case, and based on the absence of an external confining stress, the failure mode of the fibres was probably pullout (Zhu et al., 2014). The compression failure mode shown in Fig. 14, from selected specimens of the soil (A.0), soil-cement (A.2) and soil-cement-fibres (D.2.2) mixtures, is an apparent indication of the influence that the fibre's inclusion might have on the strain response. The photos presented were taken when the load reached $75 \%$ of the peak value in each test, on the post-peak (PP) segment of the stress-strain curve. It is clear that the addition of fibres allowed the specimens to sustain higher levels of deformations for the same applied percentage of stress. The no-fibre specimens (A.0 and A.2) achieved failure along a plain surface, while the fibre reinforced specimen (D.2.2) was able to carry on until excess deformation under compression was reached.

Due to the nature of the soil-fibre interaction, the tensile strength response is more prone to be affected by fibre inclusion than the compression strength. Soil particles transmit normal and shear stresses to the fibre's surface, which is then stretched until its tensile strength if fully mobilised. Only then will the effect of the

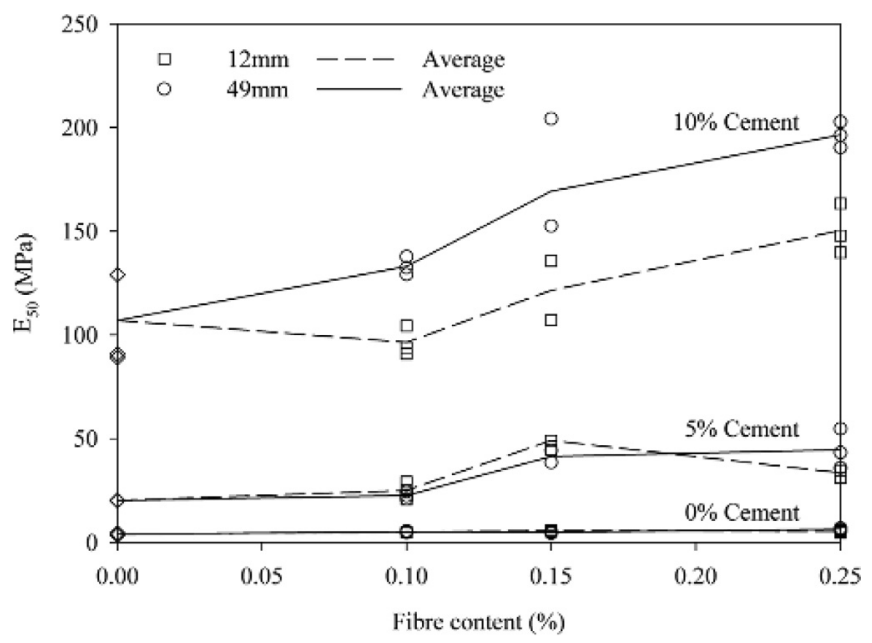

Fig. 13. Evolution of the average secant stiffness $\left(E_{50}\right)$ with fibre content.

addition of fibres reach its full potential, and thus contribute to the mechanical response of the mixture. Otherwise, i.e. if the fibre is not sufficiently strained, its contribution is less significant, especially because their stiffness is strain-dependent (Karademir and Frost, 2014). Such tensile stresses are more easily introduced in the material during tensile strength split tests than compression strength tests. However, and based on the UCS results presented in Fig. 15, there is an increase in the compression peak stress with fibre content, especially for the higher cement content of $10 \%$, and
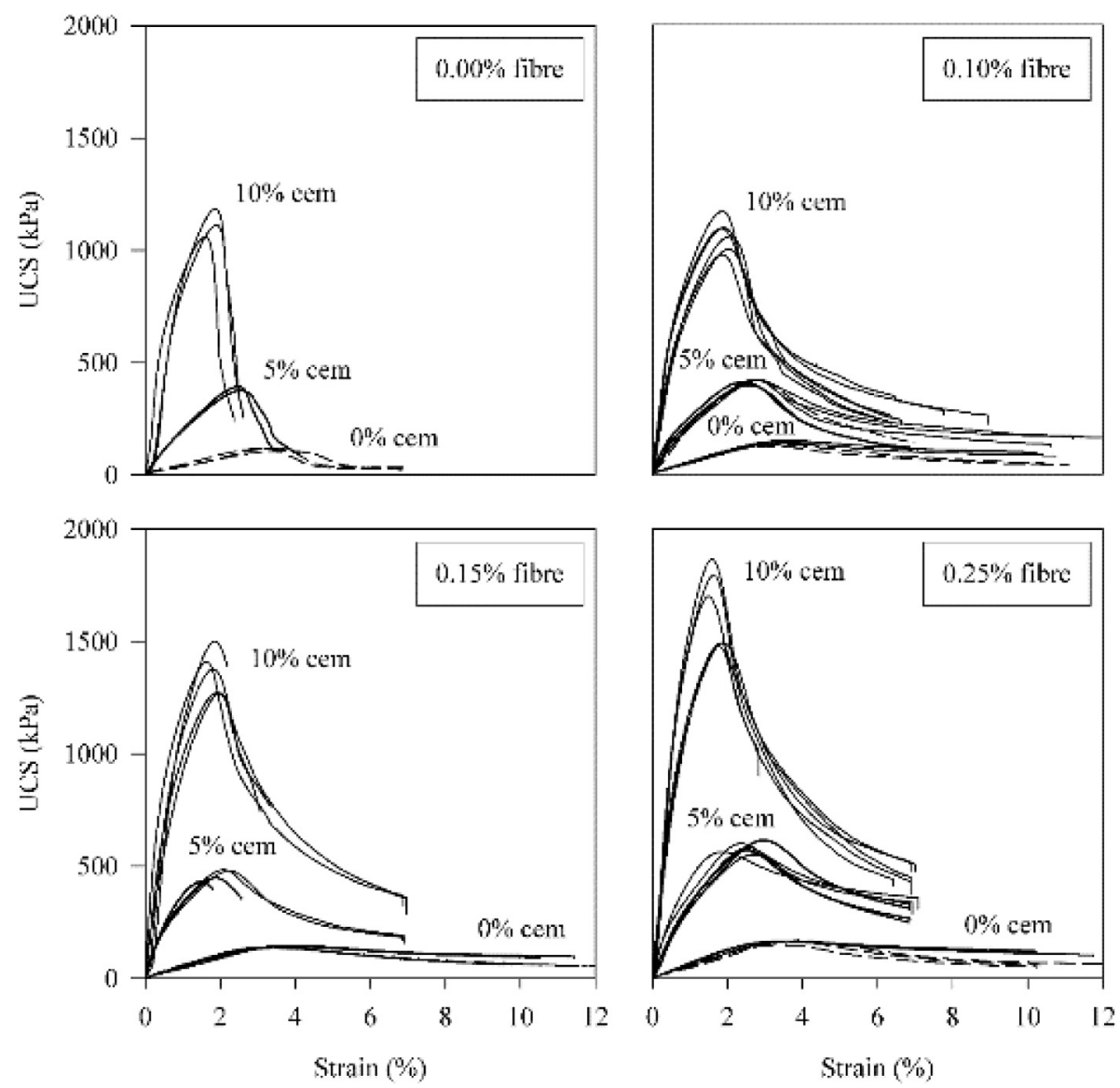

Fig. 12. Stress-strain curves of all the UCS tests. 

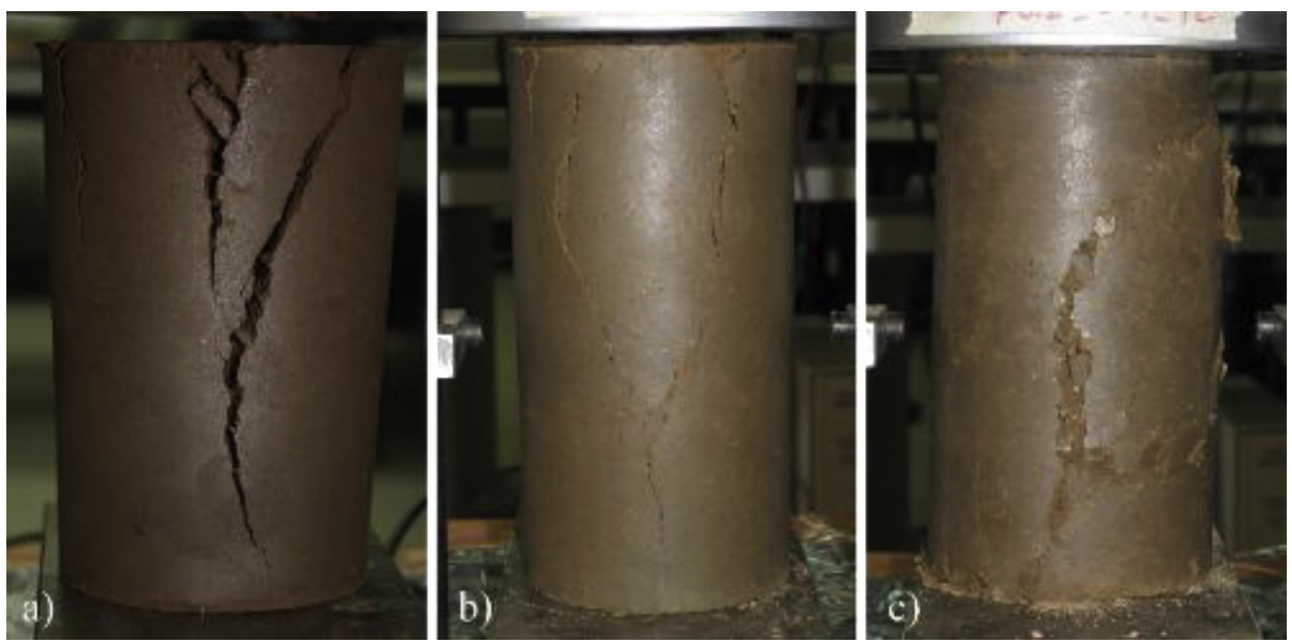

Fig. 14. Selected specimens at $75 \%$ of their respective peak stress - A.0 (a), A.2 (b), D.2.2 (c).

for fibre content above $0.10 \%$. This influence of fibre content on strength was previously attained by other authors (Estabragh et al., 2012; Li and Zornberg, 2013; Najjar et al., 2012), although some cases can also be found where the fibre content did not influence the strength levels (Freitag, 1986; Olgun, 2013), especially if fibre contents above $0.3 \%$ were used (Kumar and Singh, 2008). However, all these studies were made on non-stabilised soils, with a weaker coupling between the fibre and the confining matrix. In the present study the more ductile materials ( 0 and $5 \%$ cement) were also less influenced by the addition of fibres, while an increase in brittleness (10\% cement) represented an increase in strength (Fig. 15). Another interesting consequence of the increase in brittleness was the decrease in the range of strain, as observed in Fig. 16, which shows the peak stress as a function of the respective strain.

\section{Discussion}

\subsection{Cement content}

The cement content, as already mentioned, plays a significant role in terms of overall stress-strain response of the fibre reinforced soil. Fig. 17 shows the evolution of the average value of different deformability secant moduli as a function of the cement content. The values presented are the average results of all the tests

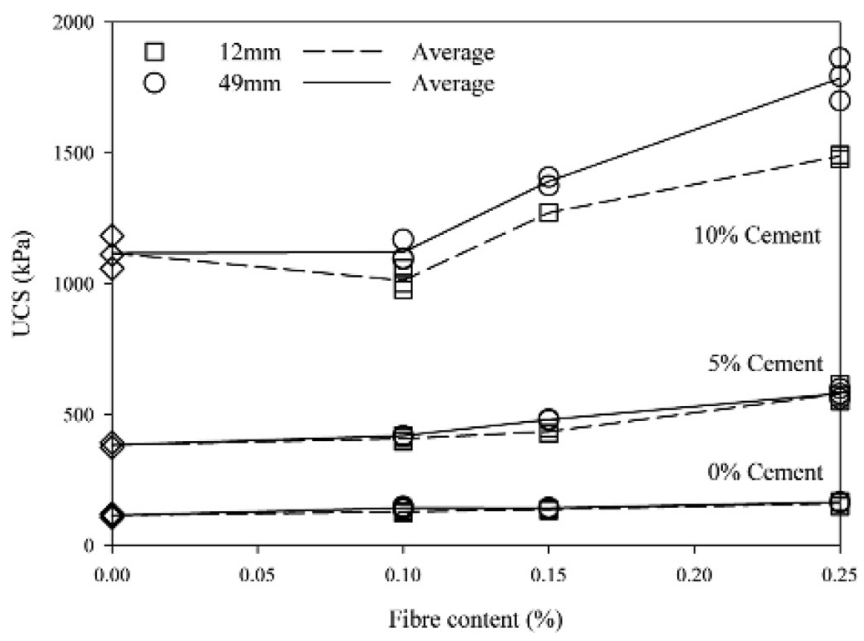

Fig. 15. Evolution of the average UCS with fibre content. performed, on the specimens with and without fibres in their constitution. An increase, with cement content, of each of the secant moduli considered can be perceived. Also clear is the decrease in the average $E$ values as the strain increases. However, while for the $0 \%$ cement mixtures such decrease is fairly constant, for the $5 \%$ and especially $10 \%$ cement mixtures there is a more abrupt reduction between the E50 and the E100, which is a consequence of the increased brittleness. Table 6 indicates the
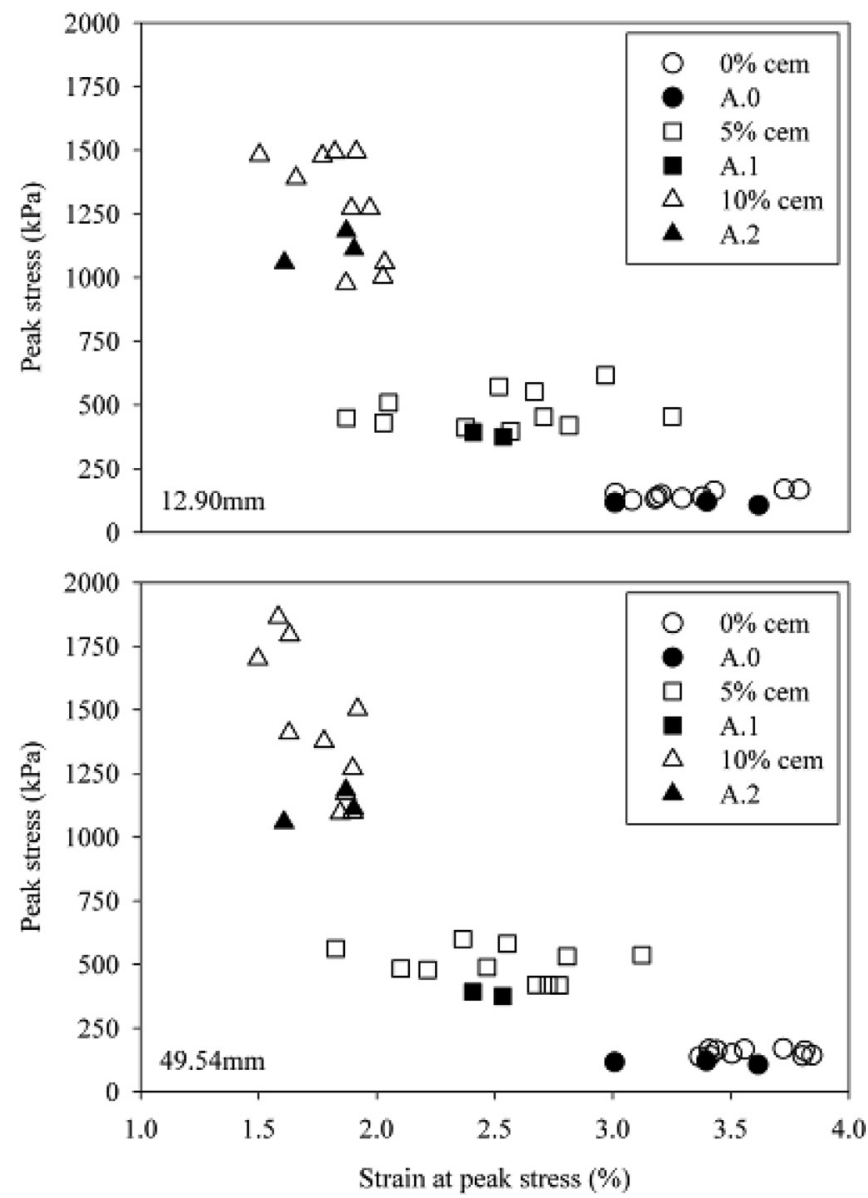

Fig. 16. Peak stress as a function of strain for $12.90 \mathrm{~mm}$ (above) and $49.54 \mathrm{~mm}$ (below) length fibres. 


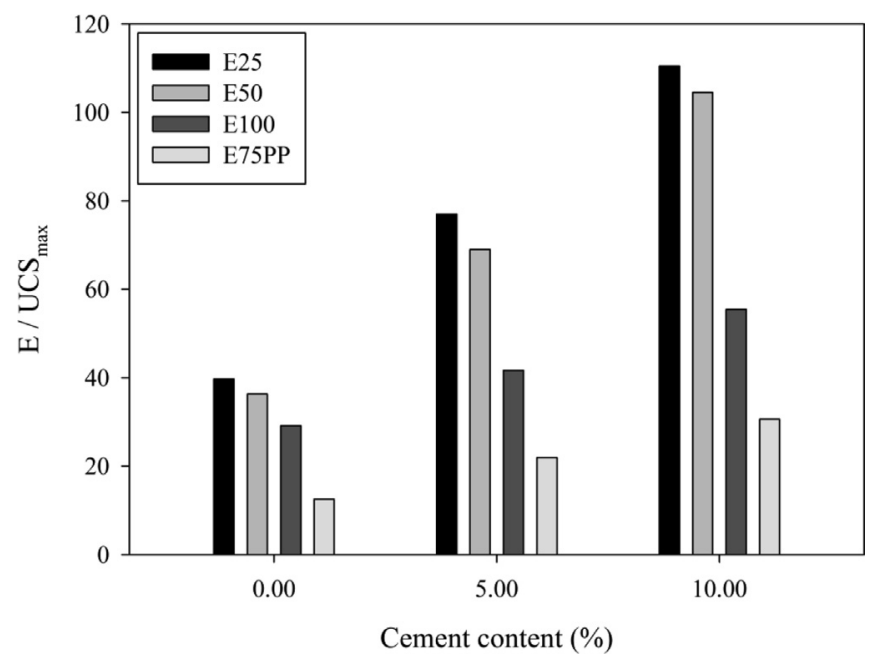

Fig. 17. Evolution of the average deformability secant modulus, normalised by the peak UCS, as a function of the cement content (values presented are the average of all the results obtained for each cement content, therefore including every fibre content).

average values of strain for each phase of the UCS test considered $(25,50,100$ and $75 \% \mathrm{PP})$. The average strain increase between the $E_{50}$ and $E_{100}$ phases of the UCS tests is more pronounced for the $10 \%$ cement mixtures $(3.69 \times)$ than for the $0 \%$ cement mixtures $(2.48 \times)$. Based on the information returned from Fig. 17 and Table 6, it is possible to conclude that the cement content is a decisive factor in terms of stress-strain behaviour.

\subsection{Fibre content}

Regarding the evolution of the deformability secant modulus, throughout the test, as a function of the fibre content, it can be seen in Fig. 18a that the addition of PP fibres did in fact contributed to the increase in stiffness of the mixture. However, in the case of the lower fibre content of $0.10 \%$, such observation is valid only for the initial phase of the stress-strain response (E25 and E50), since it presented lower E100 and E75PP values than the nofibre mixtures. In general, it can be concluded that the fibres had a more significant influence on stiffness on the early stages of the loading, which dissipated as the loading progressed. Based on these results, it appears that the maximum fibre content of $0.25 \%$ is the best option in terms of stiffness response. However, from Fig. 18b, again showing the evolution of the deformability secant modulus, only this time normalised by the maximum UCS values, it is possible to observe that the most efficient fibre content, in terms of strength and deformability, was the $0.15 \%$ value. Based on the average strain values for each loading phase $(25,50,100$ and $75 \% \mathrm{PP})$, presented in Table 7 , it is possible to conclude that the fibre content did not produce a significant influence on the early strain (25\%). However, the fibre content gained more relevance as the loading progressed, which allowed the $0.25 \%$ fibre content

Table 6

Strain at $25 \%, 50 \%, 100 \%$ and $75 \% \mathrm{PP}$ of the peak stress, as a function of the cement content (values presented are the average of all the results obtained for each cement content, therefore including every fibre content).

\begin{tabular}{|c|c|c|c|c|}
\hline \multirow[t]{2}{*}{ Cement content } & \multicolumn{4}{|c|}{ Strain $(\%)$} \\
\hline & $\mathrm{UCS}_{25}$ & $\mathrm{UCS}_{50}$ & $\mathrm{UCS}_{100}$ & $\mathrm{UCS}_{75 \mathrm{PP}}$ \\
\hline $0(\%)$ & 0.65 & 1.40 & 3.47 & 6.51 \\
\hline $5(\%)$ & 0.34 & 0.77 & 2.44 & 3.56 \\
\hline $10(\%)$ & 0.24 & 0.49 & 1.81 & 2.44 \\
\hline
\end{tabular}
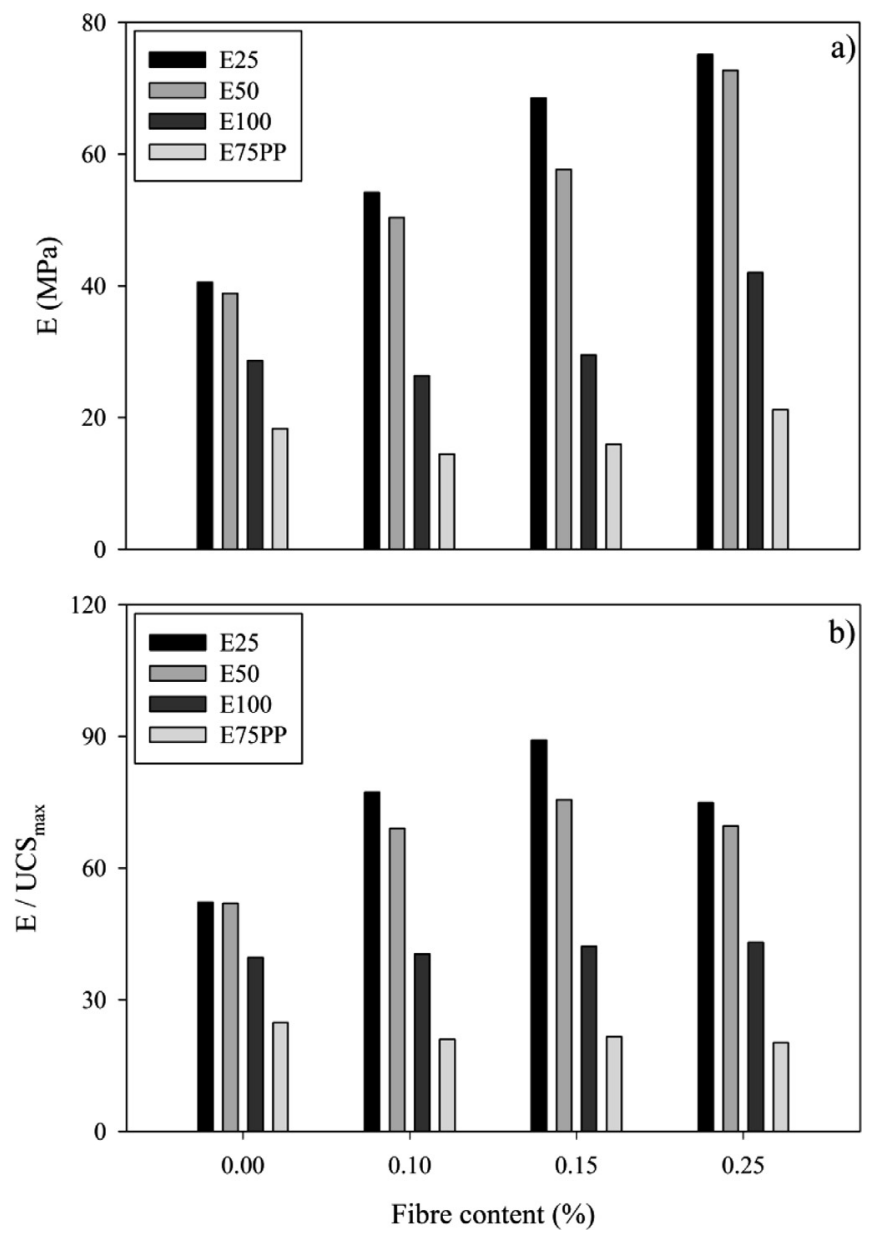

Fig. 18. Evolution of the average deformability secant modulus, without a) and with b) normalisation by the peak UCS, as a function of fibre content (values presented are the average of all the results obtained for each fibre content, therefore including every cement content).

mixtures to sustain a higher post-peak deformation (75\%PP), than the no-fibre mixtures. Based on Fig. 18 and Table 7, respectively showing a similar stiffness at $75 \% \mathrm{PP}$ and a higher strain of the $0.25 \%$ fibre content, it is possible to conclude that this parameter was influential throughout the entire loading process. Regarding the early loading stage of $25 \%$, the strain is approximately constant while the stiffness increases with fibre content. Such combination can only be achieved if the increase in fibre content produces an increase in stress levels, something which was previously confirmed in Fig. 15. For the post-peak stages of the loading, similar stiffness and different strain were recorded, something which can only be obtained with different stress values: the lower strain corresponds to the lower stress.

Table 7

Strain at $25 \%, 50 \%, 100 \%$ and $75 \% \mathrm{PP}$ of the peak stress, as a function of the fibre content (values presented are the average of all the results obtained for each fibre content, therefore including every cement content).

\begin{tabular}{|c|c|c|c|c|}
\hline \multirow[t]{2}{*}{ Fibre content } & \multicolumn{4}{|c|}{ Strain (\%) } \\
\hline & $\mathrm{UCS}_{25}$ & $\mathrm{UCS}_{50}$ & $\mathrm{UCS}_{100}$ & $\mathrm{UCS}_{75 \mathrm{PP}}$ \\
\hline $0.00(\%)$ & 0.44 & 0.97 & 2.48 & 3.00 \\
\hline $0.10(\%)$ & 0.39 & 0.82 & 2.55 & 3.96 \\
\hline $0.15(\%)$ & 0.39 & 0.86 & 2.61 & 4.43 \\
\hline $0.25(\%)$ & 0.42 & 0.89 & 2.55 & 4.52 \\
\hline
\end{tabular}




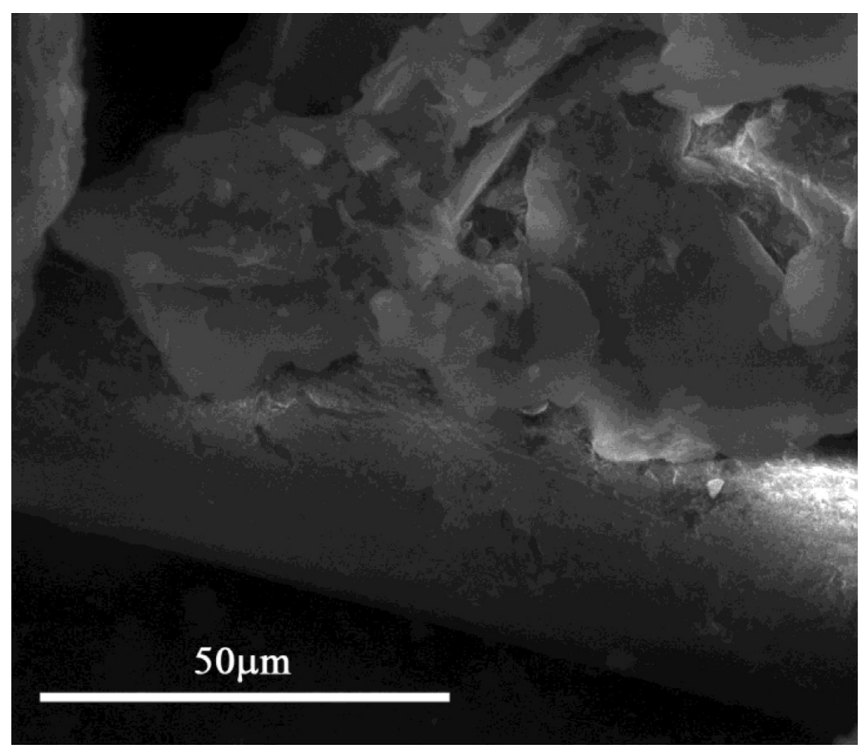

Fig. 19. SEM micrograph of a soil-fibre mixture.

\subsection{Fibre length}

As stated previously when analysing the P-wave velocity, the increase in fibre length also increases the number of contact points between the fibre and the surrounding soil particles. In fact, the number of particles in contact with the fibre is directly proportional to the fibre length, and inversely proportional to the particles mean size (Fig. 19). It is understandable that a longer fibre will interact more effectively with the soil particles, since the tensile stresses on the fibre will be able to achieve higher values if a longer embedded length is available (and assuming that the strain is enough to mobilise such tensile stresses). However, the fibres are usually in a bended position (Ibraim et al., 2012), meaning that only a smaller percentage of their length is fully stressed. Assuming that the fibre is positioned linearly in one direction, an increase in length also represents an increase in the strain necessary to fully mobilise the fibre tensile stress (assuming also that the critical embedment length is not attained, in order to avoid fibre rupture). From Fig. 20

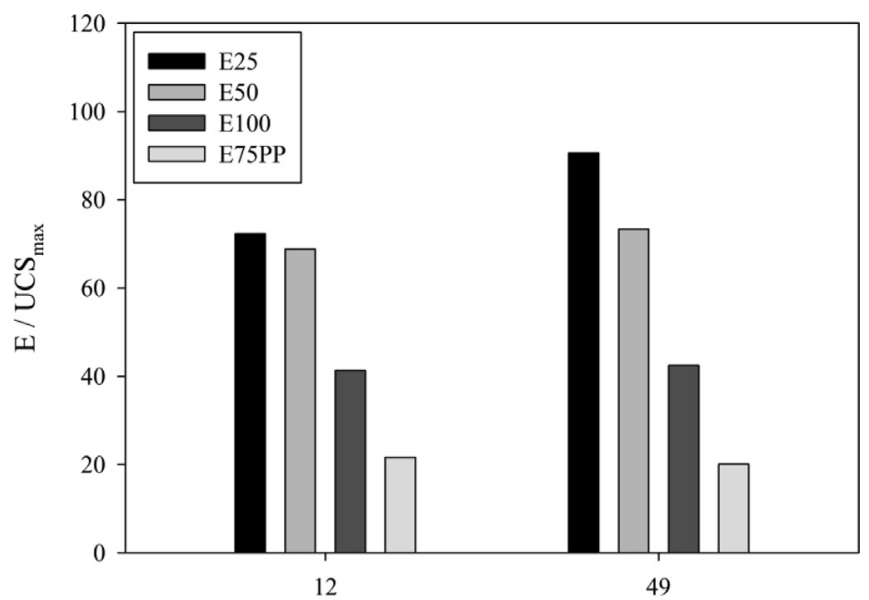

Fibre length $(\mathrm{mm})$

Fig. 20. Evolution of the normalised average deformability secant modulus throughout the test, as a function of the fibre length (values presented are the average of all the results obtained for each fibre length, therefore including every fibre and cement content). it is possible to conclude that the fibre length contributed to an increase in stiffness, but only at early stages of the loading process. As the stress-strain curve evolved, the fibre length influence on stiffness dissipates. The average strain evolution of each fibre length (Table 8) indicates similar values up until the peak stress, and a significantly higher post-peak strain for the $49 \mathrm{~mm}$ length fibre mixtures. Consequently, the $49 \mathrm{~mm}$ length fibre mixtures showed higher residual strength, i.e. ductility. The same conclusion is obtained when analysing the fibre content can be offset to the length evaluation, i.e. this parameter was influential at the extreme stages ( $25 \%$ and $75 \% \mathrm{PP}$ ) of the loading process. At the early stages of the loading, the similar strains and higher stiffness recorded for the higher fibre length is only possible with higher stresses. At the same time, the post-peak similar stiffness and higher strain recorded for the higher fibre length results can only result from higher stress levels.

\subsection{Ultrasonic wave}

Regarding the validity of the ultrasonic wave tests to estimate the dynamic deformability modulus of the soil-cement mixtures reinforced with fibres, and specifically their variation with cement content, fibre content and fibre length, it appears that the inclusion of fibres generates some disturbance. For the seismic wave velocity to be considered as an efficient method to estimate the deformability of the fibre reinforced mixtures, it should be able to rank the initial stiffness of the mixtures in the following crescent order: 0.00 , $0.10,0.15$ and $0.25 \%$ fibre content. By doing so, it would have been in accordance with what was obtained with the mechanical destructive tests. Since this was not the case, this technology should be avoided when dealing with fibre-reinforced granular materials, at least until a full understanding of the phenomena is not reached. Although the wave velocity behaviour was in partial agreement with the UCS tests data, in terms of cement content and fibre length, i.e. the wave velocity increased with an increase in cement and fibre length, it failed to sort the mixtures performance as a function of the fibre content. The faster wave velocity was not obtained for the higher fibre content $(0.25 \%)$, but was instead obtained for the lower fibre content specimens $(0.10 \%)$. Such behaviour reveals that the addition of fibres offers an alternative path, more effective in terms of wave travelling, which seems to disappear when an optimum number of fibres is achieved. When such optimum number is reached, the number of obstacles created by the additional fibres starts to dominate and the wave velocity decreases to levels below those registered for the no-fibre specimens.

\subsection{Proposed model}

The influence of fibre length on strain at peak stress was only detected for the $0 \%$ cement specimens (Fig. 16). As the brittleness of the mixture increased - 5\% and especially $10 \%$ cement - the influence of the fibres on strain at peak stress decreased. It seems that as the soil-cement matrix brittleness increases, the fibre effect is more significant during the post-peak segment of the stress-strain curve. In other words, the stiffness of the soil-cement matrix seems to

Table 8

Strain at 25\%, 50\%, $100 \%$ and $75 \% \mathrm{PP}$ of the peak stress, as a function of the fibre length (values presented are the average of all the results obtained for each fibre length, therefore including every fibre and cement content).

\begin{tabular}{|c|c|c|c|c|}
\hline \multirow[t]{2}{*}{ Fibre length } & \multicolumn{4}{|c|}{ Strain (\%) } \\
\hline & $\mathrm{UCS}_{25}$ & $\mathrm{UCS}_{50}$ & $\mathrm{UCS}_{100}$ & $\mathrm{UCS}_{75 \mathrm{PP}}$ \\
\hline $12(\mathrm{~mm})$ & 0.42 & 0.88 & 2.57 & 3.88 \\
\hline $49(\mathrm{~mm})$ & 0.40 & 0.88 & 2.61 & 4.80 \\
\hline
\end{tabular}


control the level of influence that the fibres have on the stress-strain general response of the material. With an increase in cement content the fibre influence on strength increases while its influence on strain decreases. The following behaviour is therefore proposed:

- A more ductile matrix will suffer higher strains, allowing the fibres to sustain higher deformations, and consequently have a higher influence on the overall strain.

- A more brittle matrix implies higher confining stresses and thus more contact points between the soil particles and the fibres are generated. More points mean lower distances between contact points, and lower deformations of each fibre segment between two consecutive contact points. Consequently, a more effective mobilisation of the fibre's tensile strength is achieved, resulting in greater influence of the fibres on the overall strength. This also explains why the longer fibres were able to produce higher gains in UCS than the shorter fibres, at early stages of the loading process. The longer fibres are capable to expand the active zone more effectively than the shorter fibres, thus mobilising more soil particles (Falorca and Pinto, 2011). The more rigid soil-cement surrounding is able to better "grab" the fibre, maximising the fibre pullout mobilisation, especially for the longer fibres.

- The lower influence of the fibre length and content on the strain at peak stress, when compared with the cement content, results from the higher brittleness of the soil-cement matrix, which defines the "timing" of the failure. When the soil-cement matrix yields, its influence on the overall stress-strain response drastically decreases, allowing the fibres to assume control of the process, which explains the significant strain increase at $75 \%$ PP with fibre length and fibre content. An increase in one of these two parameters allows the specimen to sustain higher deformations.
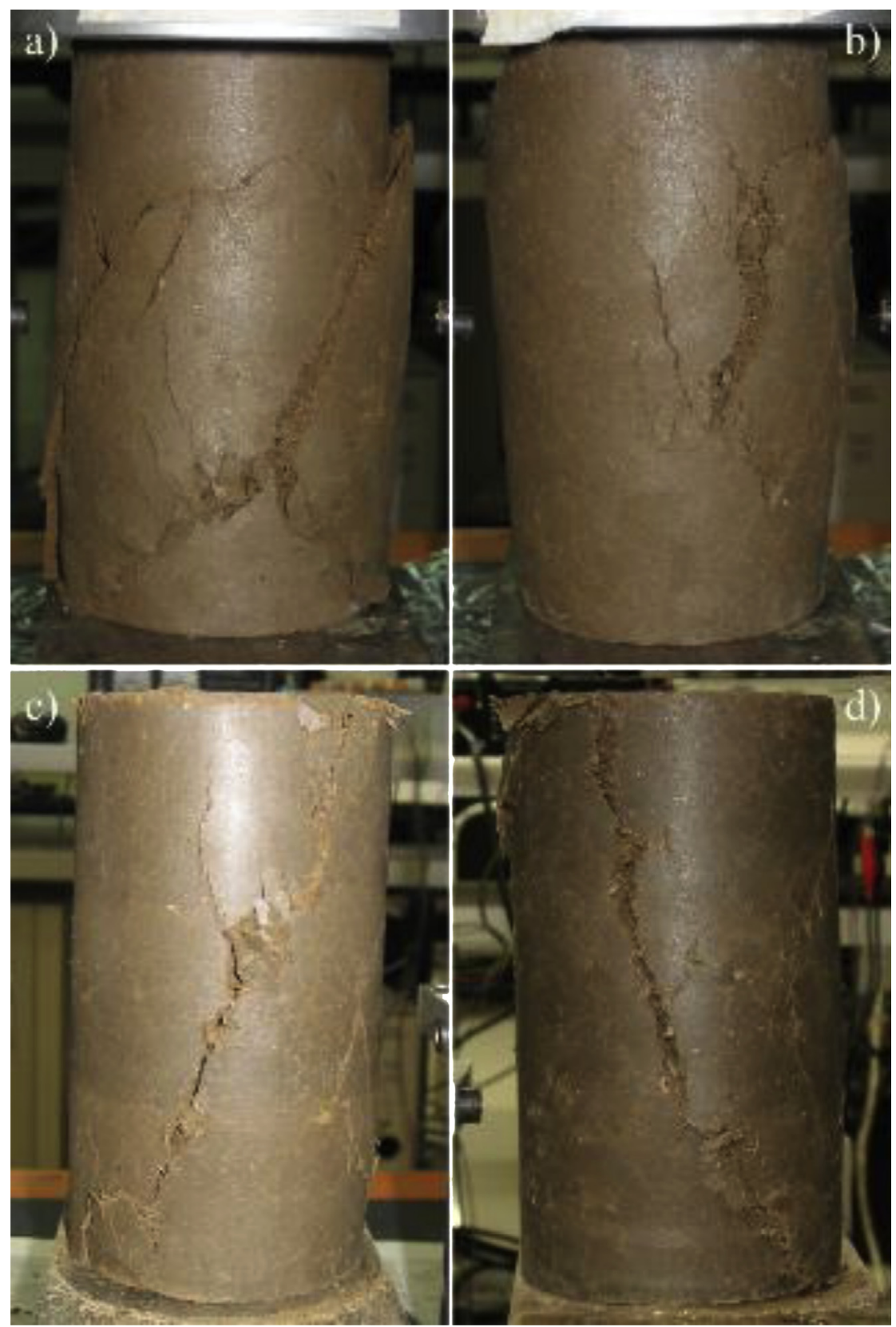

Fig. 21. Effect of fibre content ( $0.10 \%$ and $0.25 \%)$ at $75 \%$ of the peak stress on $0 \%$ cement specimens (a), (b); and $10 \%$ cement specimens (c), (d). 
The influence of fibre content on strain development is also notorious when comparing the images from Fig. 21, showing the failure mode obtained at $75 \%$ of the peak stress. It is clear that the effect of the fibres on the more ductile material (B.0.1 and D.0.1) is more pronounced than the effect seen on the more brittle material (B.2.1 and D.2.1). The increase in fibre content on the $0 \%$ cement mixtures was more effective in reducing the damage on the specimen than on the $10 \%$ cement mixtures. The described behaviour corroborates the previous statement regarding the relative effect of the fibres on the post-peak strain. Such effect is enhanced when the cementation level of the material decreases.

\section{Conclusions}

The experimental work presented in this paper was designed to study the effect of polypropylene fibres on the mechanical behaviour of a cohesive soil from the north of Portugal. The fibres were added to the soil as the single reinforcement or combined with cement. Ultrasonic wave velocity measurements were performed in order to evaluate the effectiveness of such technique in fibre reinforced materials. Uniaxial compression strength tests were also performed to characterise the mechanical behaviour of the stabilised and no stabilised clay, and in particular to better understand what the role of the fibres is at each loading stage.

Seismic wave velocity measurement appears to be an inadequate technique to evaluate the stiffness of soil-fibre mixtures, both with or without artificially cementation. This is probably related to the preferred near horizontal fibre orientation, derived from the moist tamping technique, which introduces more interfaces for the wave to cross, even with an increased in stiffness of the soil-cement matrix.

In terms of stiffness, uniaxial compression results showed that the fibres have a more significant pre-peak influence for the cemented soil, when the secant deformability modulus increases with fibre content, due to the increased peak stress. Such influence was not observed for the uncemented soil, since the deformability modulus remains practically constant with increasing fibre content.

The addition of fibres proved also to be influential in terms of strength increase. However, and although the higher fibre content showed the best strength results, it appears that there is an optimum value, in terms of strength and deformability, below the maximum fibre content.

\section{Acknowledgements}

The authors would like to acknowledge the contribution of Mrs. Paula Teixeira at the company Vimaplás, Lda, for supplying the fibres used throughout this study; and Dr. Lisete Fernandes at the Electronic Microscopy Unit of the University of Trás-os-Montes e Alto Douro, for the SEM, EDS and XRD analysis.

\section{References}

ACI 544, 2002. State-of-the-Art Report on Fiber Reinforced Concrete. ACI J. Proc. 96 Al-Refeai, T.O., 1991. Behavior of granular soils reinforced with discrete randomly oriented inclusions. Geotext. Geomembr. 10, 319-333.

ASTM, 2011. 24877-11 Standard Practice for Classification of Soils for Engineering Purposes (Unified Soil Classification System).

Banthia, N., Trottier, J., 1994. Concrete reinforced with deformed steel fibers, part I: bond-slip mechanisms. ACI Mater. J. 91, 435-446.

BSi 1377-1, 1990. BS 1377-1: 1990-Methods of Test for Soils for Civil Engineering Purposes, Part 1: General Requirements and Sample Preparation. Br. Stand. Institution, London, p. 39.

BSi 1377-2, 1990. BS 1377-2: 1990-Methods of test for soils for civil engineering purposes, Part 2: Classification Tests. Br. Stand. Institution, London, p. 2.

BSi 1377-4, 1990. BS 1377-4: 1990-Methods of Test for Soils for Civil Engineering Purposes, Part 4: Compaction-Related Tests. Br. Stand. Institution, London, p. 4.
Chauhan, M.S., Mittal, S., Mohanty, B., 2008. Performance evaluation of silty sand subgrade reinforced with fly ash and fibre. Geotext. Geomembr. 26, 429-435.

Consoli, N.C., Arcari Bassani, M.A., Festugato, L., 2010. Effect of fiber-reinforcement on the strength of cemented soils. Geotext. Geomembr. 28, 344-351.

Consoli, N.C., Prietto, P.D.M., Ulbrich, L.A., 1998. Influence of fiber and cement addition on behavior of sandy soil. J. Geotech. Geoenviron. Eng. 124, 1211-1214.

Consoli, N.C., Prietto, P.D.M., Ulbrich, L.A., 1999. The behaviour of a fibre-reinforced cemented soil. Proc. ICE - Gr. Improv. 3, 21-30.

Cunha, V.M.C.F., Barros, J.A.O., Sena-Cruz, J.M., 2010. Pullout behavior of steel fibers in self-compacting concrete. J. Mater. Civ. Eng. 22, 1-9.

Cunha, V.M.C.F., Barros, J.A.O., Sena-Cruz, J.M., 2011. An integrated approach for modelling the tensile behaviour of steel fibre reinforced self-compacting concrete. Cem. Concr. Res. 41, 64-76.

Diambra, A., Ibraim, E., Muir Wood, D., Russell, A.R., 2010. Fibre reinforced sands: experiments and modelling. Geotext. Geomembr. 28, 238-250.

Edincliler, A., Ayhan, V., 2010. Influence of tire fiber inclusions on shear strength of sand. Geosynth. Int. 17, 183-192.

Elsaid, A., Dawood, M., Seracino, R., Bobko, C., 2011. Mechanical properties of kenaf fiber reinforced concrete. Constr. Build. Mater. 25, 1991-2001.

Estabragh, A.R., Namdar, P., Javadi, A.A., 2012. Behavior of cement-stabilized clay reinforced with nylon fiber. Geosynth. Int. 19, 85-92.

Falorca, I.M.C.F.G., Pinto, M.I.M., 2011. Effect of short, randomly distributed polypropylene microfibres on shear strength behaviour of soils. Geosynth. Int. 18, 2-11.

Fatahi, B., Khabbaz, H., Fatahí, B., 2012. Mechanical characteristics of soft clay treated with fibre and cement. Geosynth. Int. 19, 252-262.

Fatahi, B., Le, T.M., Khabbaz, H., 2013. Small-strain properties of soft clay treated with fibre and cement. Geosynth. Int. 20, 286-300.

Freitag, D.R., 1986. Soil randomly reinforced with fibers. J. Geotech. Eng. 112, $823-826$

Hamidi, A., Hooresfand, M., 2013. Effect of fiber reinforcement on triaxial shear behavior of cement treated sand. Geotext. Geomembr. 36, 1-9.

Ibraim, E., Diambra, A., Russell, A.R., Muir Wood, D., 2012. Assessment of laboratory sample preparation for fibre reinforced sands. Geotext. Geomembr. 34, 69-79.

Jain, D., Kothari, A., 2012. Hair fibre reinforced concrete. Res. J. Recent Sci. 1, 128-133.

Karademir, T., Frost, J.D., 2014. Micro-scale tensile properties of single geotextile polypropylene filaments at elevated temperatures. Geotext. Geomembr. 42, 201-213.

Kopecskó, K., 2004. Durability of glass fibres. In: di Prisco, M., Felicetti, R., Plizzari, G.A. (Eds.), Proceedings of the 6th RILEM Symposium on Fibre Reinforced Concretes. RILEM Publications SARL, pp. 583-592.

Kumar, P., Singh, S., 2008. Fiber-reinforced fly ash subbases in rural roads. J. Transp. Eng. 134, 171-180.

Li, C., Zornberg, J., 2013. Mobilization of reinforcement forces in fiber-reinforced soil. J. Geotech. Geoenviron. Eng. 139, 107-115.

Lirer, S., Flora, A., Consoli, N.C., 2011. On the strength of fibre-reinforced soils. Soils Found. 51, 601-609.

Lovisa, J., Shukla, S.K., Sivakugan, N., 2010. Shear strength of randomly distributed moist fibre-reinforced sand. Geosynth. Int. 17, 100-106.

Michalowski, R.L., Čermák, J., 2003. Triaxial compression of sand reinforced with fibers. J. Geotech. Geoenviron. Eng. 129, 125-136.

Miller, C.J., Rifai, S., 2004. Fiber reinforcement for waste containment soil liners. J. Environ. Eng. 130, 891-895.

Mohamed, M.A.S., Ghorbel, E., Wardeh, G., 2010. Valorization of micro-cellulose fibers in self-compacting concrete. Constr. Build. Mater. 24, 2473-2480.

Muir Wood, D., Russell, A.R., Ibraim, E., Diambra, A., 2007. Determination of fibre orientation distribution in reinforced sands. Géotechnique 57, 623-628.

Naaman, A., Najm, H., 1991. Bond-slip mechanisms of steel fibers in concrete. ACI Mater. J. 88, 135-145.

Najjar, S., Sadek, S., Alcovero, A., 2012. Quantification of model uncertainty in shear strength predictions for fiber-reinforced sand. J. Geotech. Geoenviron. Eng. 139, 116-133.

Nataraj, M., McManis, K., 1997. Strength and deformation properties of soils reinforced with fibrillated fibers. Geosynth. Int. 4, 65-79.

Olgun, M., 2013. Effects of polypropylene fiber inclusion on the strength and volume change characteristics of cement-fly ash stabilized clay soil. Geosynth. Int. 20, 263-275.

Pinto, J., Peixoto, A., Vieira, J., Fernandes, L., Morais, J., Cunha, V.M.C.F., Varum, H., 2013. Render reinforced with textile threads. Constr. Build Mater 40, 26-32.

Ranjan, G., Vasan, R.M., Charan, H.D., 1996. Probabilistic analysis of randomly distributed fiber-reinforced soil. J. Geotech. Eng. 122, 419-426.

Savastano, H., Agopyan, V., Nolasco, A.M., Pimentel, L., 1999. Plant fibre reinforced cement components for roofing. Constr. Build. Mater. 13, 433-438.

Silva, F.D.A., Filho, R.D.T., Filho, J.D.A.M., Fairbairn, E.D.M.R., 2010. Physical and mechanical properties of durable sisal fiber-cement composites. Constr. Build. Mater. 24, 777-785.

Tang, C., Shi, B., Gao, W., Chen, F., Cai, Y., 2007. Strength and mechanical behavior of short polypropylene fiber reinforced and cement stabilized clayey soil. Geotext. Geomembr. 25, 194-202.

Tang, C.-S., Shi, B., Zhao, L.-Z., 2010. Interfacial shear strength of fiber reinforced soil. Geotext. Geomembr. 28, 54-62.

Yetimoglu, T., Salbas, O., 2003. A study on shear strength of sands reinforced with randomly distributed discrete fibers. Geotext. Geomembr. 21, 103-110.

Zhu, H.-H., Zhang, C.-C., Tang, C.-S., Shi, B., Wang, B.-J., 2014. Modeling the pullout behavior of short fiber in reinforced soil. Geotext. Geomembr. 42, 329-338. 